\title{
From cloud computing to fog computing in Healthcare big data
}

\author{
Babur Hayat Malik, Faisal Mahmood, Sohail Shahzad*, Muhammad Bilawal Arif, Waseem \\ Ur Rehman Khan, Sadaf Ilyas, and Muhammad Hassan
}

Department of Computer Sciences, University of Lahore, Gujrat Campus, Pakistan

\begin{abstract}
In Healthcare big data, data is originated from various heterogeneous sources. Numerous novel base particular healthcare applications offered to handling source of data from electronic health record (EHR) to medical images. Imaging, Electronic Health Report, technology in light of sensor and numerous different procedures created an immense measure of Healthcare data. Cloud computing development was an excellent paradigm to substantiate big data which incited find of imperceptible examples. Cloud computing is a developing new registering design intended to answer different contending administrations on the Web. Fog Computing is a design style in which arrange segments amongst devices and the cloud execute application-particular rationale. We in this paper investigate, characterize, and talk about various application of cloud and fog computing. We talk about the impact of cloud computing and fog computing on healthcare big data. Cloud base framework for Homediagnosis Service, Fog computing architecture and the justification of moving from cloud to Fog presented comprehensively in this paper.
\end{abstract}

\section{Introduction}

Healthcare stands before its most central changes ever. Wireless sensor technology is one driver of these progressions [1]. The healthcare business is producing huge measure of data [2]. We can state that advances in innovative based condition has assessed and investigated data utilizing capacity instruments for forecast of future results [3]. Huge development of the big data is setting out powerful programming and equipment association to grasp with current difficulties and find looming devices for future investigation [4]. Cloud and IoT advances speak to the absolute most intense leaps forward in figuring of the most recent years [5]. Nonetheless, current cloud computing models don't appear the best answer for handling to the challenges of IoT, meanwhile high bandwidth requirements [6]. The dissemination of figuring is useful, as it offloads distinctive undertakings and procedures on every one of the segments of the system, with bring down necessities on bandwidth and capacity abilities [7].

Over the few last decade, the data growth from Internet of Things (IoT), multimedia, and different sensing devices introduce a huge amount of data in unstructured, semi structured or structured format called big data [8]. IoT brings weighty advantages over

* Corresponding author: sohail.shahzad54@gmail.com 
traditional communication technologies in Healthcare sector [9]. IoT based medical file cloud storage system which control and secure deduplication and also provide facility to manage the data in EHS [10]. There is a critical number of registering errands in the industry of healthcare that require profit by fog-computing principles [11].

\section{The impact of big data in healthcare}

In healthcare area, the ramifications of the big data serve prescient analytical procedures and machine learning stages for the arrangement of practical arrangements, for example, the execution of treatment designs and customized medicinal care [12]. They reclassified the characteristics of the big data into main three highlights to be specific Silo, Security, and Variety rather than Volume, Variety and Velocity [13]. Silo speaks to the bequest database that contains open healthcare data Kept up in partners' premises, for example, healing centers [14]. A run of the mill persistent driven healthcare biological community with its huge partners and their differentiated data sources which are (structured type, semistructured type and unstructured type) is seen in below figure 1.

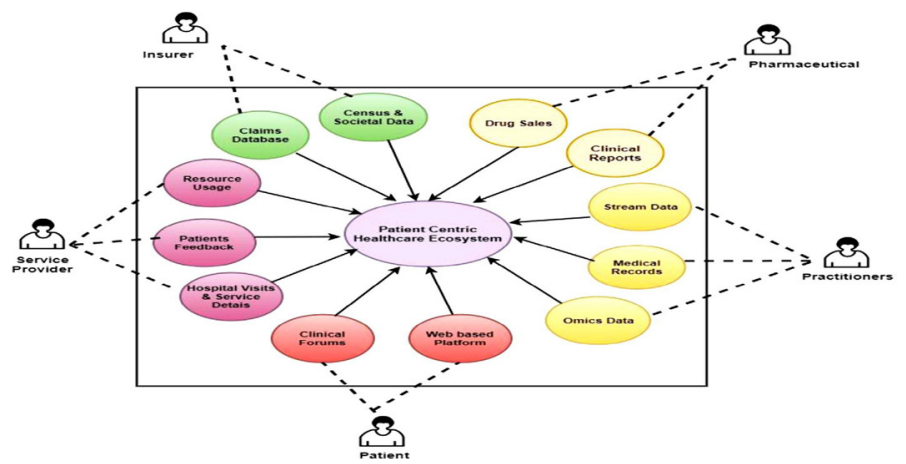

Fig. 1. The ecosystem of Patient centric healthcare "From the viewpoint of big data" [13].

In Patient driven healthcare ecosystem with its noteworthy partners and their broadened data sources works cooperatively and share their data with Patients, Practitioners, pharmaceutical, hospital operators and service Provider's experiences successfully.

\section{An integration of cloud computing and healthcare big data}

Today Information Technology's major structures are moving toward technology based on cloud and its administrations for handling of big data. The real issue looked by healthcare specialist and researchers is "Big Data"[2]. It compares to $4 \mathrm{~V}^{\prime} \mathrm{s}$, that incorporates velocity at data is originating in healthcare utilization area. Data generated by these different assets are consists of data of various types which is extremely hard to be overseen by capacities of human in solitude, likewise with same velocity, volume of the data is increasing [3].

\section{A framework based on cloud for Home-Diagnosis service}

Big data give the office since it has historic clinical records, and to get determination independent from anyone else with comparable patient's records [15]. In addition, this administration gives the detail, indications of infection and ailment insurance information from chronicled therapeutic records [16]. There are 4 stages in this administration, in first the patient send query, second the patient record data analysed with authentic restorative 
records, third at that point process an ailment manifestation grid and fourth gives the detailed diagnosis analysis premise to client [17].

\subsection{Home-Diagnosis service's implementation}

The execution of service of the Home-diagnosis comprises of 4 stages [16].

- Query submission: In this progression, an objective client presents a client query, the heap balancer sends the information to a specific deputed dispatcher [16].

- Retrieval of Medical-records: The deputed dispatcher chosen arrangement of search nodes to discover medical records coordinated the client query.

- Data analysis: The data analysis hub will figure the disease-symptom cross section related with the medical records recovered in the Step number 2.

- Filtering the privacy information on returned results: In this sub step, from medical records the patient's privacy information is separated by the target client's access authority.

\section{Internet of Things}

"The Internet of Things (IoT) envisions pervasive, connected, and smart nodes interacting autonomously while offering all sorts of services" [18]. IoT is provide the way for utilization in different areas such as security and surveillance, healthcare, industry, transportation and also integrate with advance technology of communication, cloud computing, networking, sensing and actuation [19].

\section{Fog computing}

Mostly cloud computing centres of topographically concentrated and the data centres are not closed situated to the user are devices [20], for this the fog computing term is used [21]. Another term used is edge computing [22]. The intelligence of fog-computing is idea behind of calculation offloading [23], Edge-assisted is referring to the incorporate with different fog nodes that transfer the data of restorative and healthcare, through IoT [24].

\subsection{Fog computing architecture}

The advance version of Cloud computing is Fog computing suitable for the geological division of resources other than unified one. In figure 2 all smart appliances are connected with Fog Computing, means it also supports mobility. In Fog Computing platform multitier architecture used. The $1^{\text {st }}$ tier is used for machine to machine communication and the higher tiers deals with visualization and reporting.

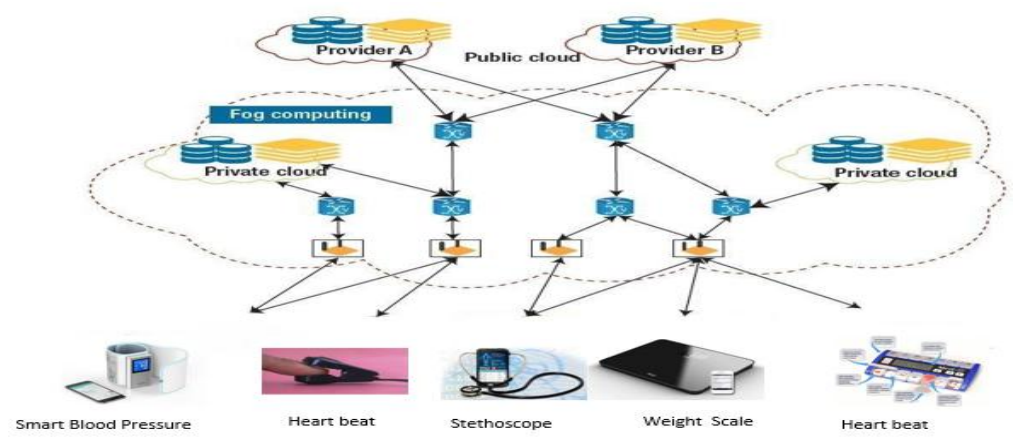

Fig. 2. Fog Computing Architecture [25]. 


\subsection{Features of fog computing}

- Heterogeneity: Fog computing is a platform that offers different services between the cloud computing and the end nodes.

- Geographical distribution: It has a broadly circulated sending keeping in mind the end goal to convey fantastic administrations to both fixed and mobile end devices.

- Edge location and low latency: The rise of fog-computing is mostly because of the lack of help for end points with quality administrations at the system's edge.

- Real-time interaction: Many applications of Fog Computing, for example real-time traffic monitoring systems, instead of batch processing.

- Support for mobility: The hold of mobility is fundamental for some, fog-computing applications to empower coordinate correspondence with different mobile devices utilizing protocols.

- Large-scale sensor networks: This is relevant when monitoring nature or in smart grid utilizing inalienably distributed systems that require distributed computing and storage resources.

- Prevalent to wireless access: The examples of Fog network node are cellular mobile gateway and Wireless access points.

- Interoperability: Fog-components must have the capacity to interoperate to guarantee bolster for extensive variety of services for example data streaming.

\section{Comparison of Fog, Cloud and loT features}

Table 1 summarizes the features associated with fog \& cloud computing and IoT.

Table 1. Summary of Fog, cloud and IoT feature [26, 27].

\begin{tabular}{|c|c|c|c|}
\hline Features & Fog & Cloud & IoT \\
\hline Target User & Mobile users & User of General Internet & $\begin{array}{c}\text { Stationary and mobile } \\
\text { devices }\end{array}$ \\
\hline $\begin{array}{l}\text { Quantity of } \\
\text { server nodes }\end{array}$ & Huge & Limited & Huge \\
\hline Architecture & Distributed & Centralized & $\begin{array}{l}\text { Distributed and } \\
\text { Dense }\end{array}$ \\
\hline $\begin{array}{l}\text { Type of } \\
\text { Service }\end{array}$ & $\begin{array}{l}\text { Localized information } \\
\text { service limited to specific } \\
\text { deployment location }\end{array}$ & $\begin{array}{l}\text { Global information } \\
\text { collected worldwide }\end{array}$ & $\begin{array}{l}\text { Information specific } \\
\text { to the end device }\end{array}$ \\
\hline $\begin{array}{l}\text { Working } \\
\text { environment }\end{array}$ & $\begin{array}{l}\text { Outdoors or Indoors } \\
\text { respectively Streets fields } \\
\text { tracks and home, restaurants } \\
\text { \& malls. }\end{array}$ & $\begin{array}{l}\text { Indoors with massive } \\
\text { space and ventilation }\end{array}$ & Outdoor and Indoor \\
\hline $\begin{array}{l}\text { Location } \\
\text { awareness }\end{array}$ & Yes & No & Yes \\
\hline $\begin{array}{c}\text { Real-time } \\
\text { interactions }\end{array}$ & This system supported & This system supported & $\begin{array}{l}\text { This system } \\
\text { supported }\end{array}$ \\
\hline Mobility & This system supported & $\begin{array}{l}\text { Limited supported } \\
\text { system }\end{array}$ & $\begin{array}{l}\text { This system } \\
\text { supported }\end{array}$ \\
\hline $\begin{array}{c}\text { Time of } \\
\text { storage and } \\
\text { Big data } \\
\end{array}$ & $\begin{array}{l}\text { Short duration as it } \\
\text { transmits big data }\end{array}$ & $\begin{array}{l}\text { Months and years as it } \\
\text { manages big data }\end{array}$ & $\begin{array}{l}\text { Transient as it is the } \\
\text { source of big data }\end{array}$ \\
\hline $\begin{array}{l}\text { Major service } \\
\text { provider }\end{array}$ & Cisco IOx & $\begin{array}{l}\text { IBM, Microsoft, } \\
\text { Amazon }\end{array}$ & Bosch, Atmel, ARM \\
\hline
\end{tabular}




\subsection{Benefits}

- Gets the data close to the user: The data is close to the end-user because of Fog Computing, instead of cloud computing in which the data center's far from the end-point.

- Creates dense geographical distribution: 1) analytics and big-data can be done faster with better outcomes. 2) Management able to support location-based mobility demands which is not pass through all over the network. 3) Fog system is a simplest way for real time data analytics.

- Internet of Everything and mobility's true support: Fog computing combines cloud services with distributed data centres by controlling data at different nodes. Fog computing networks become more powerful by providing end user benefits.

- Many companies ready to adopt: Different organizations adopting the Fog Computing which delivers various services and provides rich content to the end user destination that extents vendors, IT shops and different companies as well.

- Combinations of cloud with others services: By dividing the data of user which needs to be active on the edge we are capable to improve the cloud experience.

\section{Healthcare application's requirements}

Fog computing is important and have many benefits for healthcare industry. But We epitomize the corresponding requirements.

- Bandwidth: There are numbers of different principals for different physiological signals bit rate, the quantization step size of Analog to Digital converter in bits and also sampling the frequency [28]. A normal human body required a low sampling frequency about $0.2 \mathrm{~Hz}$. The results in a bit rate of $2.4 \mathrm{bit} / \mathrm{s}$ show on 12-bit ADC [29].

- Latency: For ECG, the experiments with cardiologists show that the latencies of up to ( $2 \mathrm{Sec}$ to $4 \mathrm{Sec}$ ) in real-time monitoring are satisfactory but the results are relatively slack [30].

- Energy Efficiency: Energy efficiency have the main role in this domain, sometimes battery replacing process create problems specially in body sensors which may require an operation [31].

- Dependability: Dependability is also having an important requirement to consider. If the system fails, in different conditions a minor disturbance make serious threats to the patients' lives.

- Security: Patient data is very sensitive, the security requirements are increased in this situation when the sensitive data is transferred, especially in remotely monitoring of devices which attains the larger attacks [32].

- Interoperability: Some times Cardiologie patients, for instance, when they are transport between the different section in a hospital, who require a sensitive monitoring system via ECG. This system should be having compatibility to different hardwares during transfer [28].

\section{Issues and challenges in healthcare}

- Self-caring service: This service assists the user with a small number of Historical Medical Records at home. There is no service for more people with different types of disease which have the supporting potential to get diagnosis references.

- Real-time data monitoring system: How to develop and design a system which monitor the data on Real time in fog computing. The reason is that the eHealth system is a 
very complex task because of login of users through applications, remotely access and monitoring the data, and information exchange between different heterogenous entities.

- Real-time streaming engine: This is also on issue to access the real time data that the user can monitor their health data easily. There is need to be real time streaming engine.

- Data sources: Machines are only work on the experience of experts. Data collection from the better data sources will be required in future.

- Limited data storage: In health care applications there is no real time analytical system as like in cloud computing which have computing, storing and network services.

- Security issues: Some Patients are not provided the actual data about health to experts for research use. The reason is data security issues.

\section{Conclusions}

Our review places some practical implication in healthcare system using smart healthcare applications. These applications are connected to the cloud via the sensors. The main objectives of this paper were to acknowledge how the Cloud and Fog Computing can give various benefits in the field of healthcare applications. The fog computing is sharing more part in current scenario of healthcare architecture. The significant role of the fog computing over the cloud computing is giving the benefits to effectively use the healthcare system. These benefits are decreasing the amount of unnecessary expenses to improve the infrastructure of system. The fog computing is encompassing the benefits of cloud computing to support all IoT devices.

\section{References}

1. Kraemer, F.A., Braten, A.E., Tamkittikhun, N., and Palma, D.: 'Fog Computing in Healthcare-A Review and Discussion', IEEE Access, 2017, 5, pp. 9206-9222

2. Duhigg, C.: 'The power of habit: Why we do what we do in life and business' (Random House, 2012)

3. Hellerstein, J.: 'Parallel programming in the age of big data. Gigaom Blog (2008).

4. Ursum, J., Bos, W.H., van de Stadt, R.J., Dijkmans, B.A., and V.Schaardenburg, 'Different properties of ACPA and IgM-RF derived from a large dataset: further evidence of two distinct autoantibody systems', (2009), 11, (3).

5. Cerina, L., Notargiacomo, S., Paccanit, M.G., and Santambrogio, M.D.: 'A fogcomputing architecture for preventive healthcare and assisted living in smart ambients', in Editor (Ed.) ^(Eds.): (IEEE, 2017, edn.), pp. 1-6

6. Manyika, J., Chui, M., Bisson, P., Woetzel, J., Dobbs, R., Bughin, J., and Aharon, D.: 'Unlocking the Potential of the Internet of Things', McKinsey Global Institute, 2015

7. Bauer, H., Patel, M., and Veira, J.: 'The Internet of Things: Sizing up the opportunity', Retrieved from: McKinsey in, (2014)

8. Van-Dai Ta, C.-M.L., Goodwill Wandile Nkabinde: 'Big Data Stream Computing in Healthcare Real-Time Analytics', IEEE, (2016)

9. Yang Yang, X.Z., Wenzhong Guo, Ximeng Liu, Victor Chang: 'Privacy-Preserving Fusion of IoT and Big Data for E-health', (2017)

10. Yang, X.Z., W. Guo, X. Liu,V.Chang: 'Privacy-preserving smart IoT-based healthcare big data storage and self-adaptive access control system', ELSEVIER

11. E.Topal: 'The Creative Destruction of medicine', (2013) 
12. Al-Jarrah, O.Y., Yoo, P.D., Muhaidat, S., Karagiannidis, G.K., and Taha, K.: 'Efficient machine learning for big data: A review', Big Data Research, (2015, 2, 3).

13. V.Palanisamy \& R.Thirunavukarasu:'Implications of Big Data Analytics in developing Healthcare Frameworks-A review', King Saud University (2017)

14. L.Wang, and C.A. Alexander.: 'Big data in medical applications and health care', American Medical Journal, (2015), 6, (1), pp. 1

15. Zhang, Y., Qiu, M., Tsai, C.-W., Hassan, M.M., and Alamri, A.: 'Health-CPS: Healthcare cyber-physical system assisted by cloud and big data', IEEE (2017), 11.

16. Lin, W., Dou, W., Zhou, Z., and Liu, C.: 'A cloud-based framework for Homediagnosis service over big medical data', Journal of Systems and Software, (2015).102

17. He, C., Fan, X., and Li, Y.: 'Toward ubiquitous healthcare services with a novel efficient cloud platform', IEEE Transactions on Biomedical Engineering, (2013), 60.

18. Conti, M., Dehghantanha, A., Franke, K., and Watson, S.: 'Internet of Things security and forensics: Challenges and opportunities', in Editor (Ed.) ^(Eds.): 'Book Internet of Things security and forensics: Challenges and opportunities’ (Elsevier, 2018, edn.), pp.

19. Oracevic, A., Dilek, S., and Ozdemir, S.: 'Security in internet of things: A survey', in Editor (Ed.) ^(Eds.): ‘Book Security in internet of things: A survey’ (IEEE, 2017, edn.)

20. Mahmud, R., Kotagiri, R., and Buyya, R.: 'Fog computing: A taxonomy, survey and future directions': 'Internet of Everything' (Springer, 2018), pp. 103-130

21. Bonomi, F., Milito, R., Zhu, J., and Addepalli, S.: 'Fog computing and its role in the internet of things', in Editor (Ed.) ^(Eds.): 'Book Fog computing and its role in the internet of things' (ACM, 2012, edn.), pp. 13-16

22. Hu, Y.C., Patel, M., Sabella, D., Sprecher, N., and Young, V.: 'Mobile edge computing - A key technology towards 5G', ETSI white paper, (2015), 11, pp.1-16

23. Fernando, N., Loke, S.W., and Rahayu, W.: 'Mobile cloud computing: A survey', Future generation computer systems, (2013), 29, (1), pp. 84-106

24. Barik, R.K., Dubey, H., Misra, ... 'Fog Assisted Cloud Computing in Era of Big Data and Internet-of-Things: Systems, Architectures, and Applications' (Springer, 2018).

25. Dastjerdi, A.V., and Buyya, R.: 'Fog computing: Helping the Internet of Things realize its potential', Computer, (2016), 49, (8), pp. 112-116

26. Osanaiye, O., Chen, S., Yan, Z., Lu, R., Choo and Dlodlo, M.: 'From cloud to fog computing: A review and a conceptual live VM migration framework', IEEE (2017), 5

27. Apexa A. Dabhi, P.T.J.R., Prof. K. Chaudhary: 'Fog computing: A review and conceptual architecture, issues, applications and its challenges', IJARIIE-ISSN(O)2395-4396, (2017), 3

28. Eide, R.B.: 'Low Energy Wireless ECG-An exploration of wireless electrocardiography and the utilization of low energy sensors for clinical ambulatory patient monitoring', NTNU, (2016)

29. Paksuniemi, M., Sorvoja, H., Alasaarela, E., and Myllyla, R.:(IEEE, 2006, edn.)

30. Alesanco, A., and García, J.: 'Clinical assessment of wireless ECG transmission in real-time cardiac telemonitoring', IEEE, (2010), 14, (5), pp. 1144-1152

31. Movassaghi, S., Abolhasan, M., Lipman, J., Smith, D., and Jamalipour, A.: 'Wireless body area networks: A survey', IEEE Communications Surveys \& Tutorials, (2014)

32. Sametinger, J., and Rozenblit, J.W.: 'Security Scores for Medical Devices', in Editor (Ed.) ^(Eds.): 'Book Security Scores for Medical Devices’ (2016, edn.), pp. 533-541 